\title{
Possible, Probable and Preferable Futures of the Digital Divide
}

\author{
Matthew M. Mitchell \\ Washington State University, Pullman, WA, USA
}

matthew mitchell@wsu.edu

\begin{abstract}
The digital divide is widely recognized as a contemporary problem between society and technology. Strategies for bridging the digital divide are often informed and guided by quantitative assessments of the deployment of information communication technologies. There are few rigorous qualitative attempts to assess the digital divide from either an ethnographic or a futures-oriented perspective. This paper reports findings from a study that examined the possible, probable and preferable futures of the digital divide from an ethnographic perspective. The contents of this report include background to the problem of the digital divide, a review of literature describing the relationship between society and technology, findings from the data collection, and implications for future strategies to bridge the digital divide.
\end{abstract}

Keywords : Digital Divide, Public Policy, Information Communication Technologies (ICT), Society and Technology, Qualitative Research

\section{Introduction}

The problem of the digital divide receives much attention in both local and global contexts. Many researchers, practitioners and policy makers have explored this multi-facetted and pervasive inequity in unique and helpful ways. There appears to be consensus among the growing volume of studies and critical inquiries that the digital divide is a socio-economic divide driven by the rapid evolution and proliferation of electronic technologies designed to communicate information (information communication technologies, ICT). In recent years, community activists, policy makers and business leaders, among others, have recognized the digital divide as a significant social problem that must be addressed. Despite such widespread agreement in identifying this ICT-induced schism, local and global strategies for ameliorating the digital divide appear to be disconnected and largely reactive.

Efforts to understand the digital divide usually rely on the longitudinal collection and analysis of key indicators that are used as mile markers en route to establishing an inclusive information society. Additionally, these ind icators are regularly used to set targets for development and guides for public policy. Examples of these data points include the serial measurement of penetration rates of telephones, computers and Internet connections. Other indicators frequently used for describing and understanding the digital divide include such aspects of connectivity like processing speed, bandwidth, and cost and convenience of access. These data points are usually broken down for a broad array of demographic catego-

Material published as part of these proceedings, either on-line or in print, is copyrighted by Informing Science. Permission to make digital or paper copy of part or all of these works for personal or classroom use is granted without fee provided that the copies are not made or distributed for profit or commercial advantage AND that copies 1) bear this notice in full and 2) give the full citation on the first page. It is permissible to abstract these works so long as credit is given. To copy in all other cases or to republish or to post on a server or to redistribute to lists requires specific permission from the publisher at Publisher@InformingScience.org ries (e.g., race, income, education, geographic, etc.). The majority of past efforts to monitor the digital divide are aggregations of quantitative indices. In both theory and practice, there are few attempts to qualitatively explore strategies for bridging the digital divide, especially from either ethnographic or futurist perspectives, let alone both. 
In this paper, findings from an ethnographic futures research project that explored the digital divide are reported through the lens of the interactive relationship between society and technology. Before presenting these findings, this paper first reviews a selection of literature elucidating the technology-society relationship. Next, a brief overview describes how this research method was implemented. Finally, a group of findings from this research project will be presented that are relevant to the summarized literature. Concluding this paper is a discussion of the implications these findings have on strategies for brid ging the digital divide.

\section{Technology and Society}

Harvard Professor Jacob Bigelow is credited with having coined the term technology in 1820 (Volti, 1995, 2001). Despite the relative youth of the term in the English language, technology's influential relationship with society arguably reaches back to the beginning of human history. Concerning the history of technology, a number of authors believe the development of human organization from the Eolithic Age to the Information Age is directly related to the development of technology (Burke, 1985, p. 13; McNeil, 1996, p. 5; Volti, p. 127). Rutherford and Ahlgren (1990) suggest,

Technology is a complex social enterprise that includes not only research, design, and crafts but also finance, manufacturing, management, labor, marketing, and maintenance. In the broadest sense, technology extends our abilities to change the world: to cut, shape, or put together materials; to move things from one place to another; to reach farther with our hands, voices, and senses. (p. 23)

Since the human race began, technology has played a distinct role in humanity's development. Ihde (1990) asks us to consider a very basic question concerning humanity's relationship with technology: "Could humans live without technologies?" (p. 11). His answer, based on empirical and historical fact, is simply no. Qualifying his conclusion, Ihde notes that "there are no known peoples, now or in historic or even prehistoric times, who have not possessed technologies in some minimal sense" (p. 11). Throughout human history, developments in techniques, manifested in both artifacts and processes, have accompanied developments in civilization. Consider the importance of the following techniques (McNeil, 1996, pp. 5-42, 762-766):

1. The practice of making simple stone tools led the way to weapon production for hunting and protection.

2. The ability to make and use fire, mastered in China around 600,000 B.C., enabled humans to produce heat, cure hides, cook, and gather after darkness.

3. Plant domestication, animal husbandry, and soil plowing (i.e., agrarian technologies) made it possible for humans to produce food surpluses that eventually allowed societies to form permanent, sedentary communities.

4. Writing and printing techniques aided human memory and changed the human ability to communicate and record history.

5. The harnessing of steam power is credited with the development of factories and launching the Industrial Revolution.

6. The inventions of electricity and transistors have accelerated human societies into what is commonly called the Electronic Age.

Human history is replete with numerous technological advances that impact the way people survive. Technology may be viewed as an integral component of human nature. Alcorn (1997) suggests that technology is what distinguishes Homo sapiens from all other species: "the difference between humans and other animals lies in the way the organism goes about the processes of adaptation and specialization" (p. 
tion" (p. 14). Technology, as described by Alcorn, is a reflection of humanity's remarkable propensity to adapt innovate and imitate; "We are the ultimate simulator in nature" (p. 226).

As human dependency on technology has evolved, so have attitudes toward technology. In modern times, technology has tacitly been connected to the notion of progress. Explaining this stance, Ihde (1993) describes how a "rational and progressive set of beliefs have come into being through science, which in its applications to technologies will (eventually) solve most human problems" (p. 60). Ihde suggests that the notion of utopian progressivism is linked to the roots of modernity (i.e., the late Renaissance). Capitalizing on the notion of progressivism, the eighteenth century (i.e., the Enlightenment) became a period "in which the rhetoric of 'conquering Nature itself' became quite rampant" (p. 61). Quantitative measurements are often used to demonstrate the unambiguous progress of technology. Consider the following examples (pp. 60-61):

1. Life expectancy is longer now than in any other period in human history.

2. The standard of living is higher now than ever before.

3. Quality of food and health is at an all-time high.

4. Disease and illness are being cured in record numbers.

5. Communication and travel are becoming easier and more rapid.

Growing increasingly skeptical, dystopian thinkers have begun to voice their own quantitative assessment of technology's progress (Ihde, 1993, p. 62). For example, in 1962, Rachael Carson published Silent Spring, in which she shattered society's faith in insecticides such as DDT. Ralph Nader, in 1965, published Unsafe at Any Speed, which documented the inherent dangers of General Motors' Corvair passenger vehicle. Ihde asserts that over time attitudes toward technology have changed, and will likely continue to change as culture changes. Because, according to Ihde, "all technologies are embedded in culture" (p. 64).

\section{Technological Fix}

Technology has been employed to mediate many social problems (Borgmann, 1992). The question posed by many critical thinkers is whether technological fixes are sufficient for solving social maladies. Exploring this question, Etzioni and Remp (1972) reviewed a collection of studies detailing how six distinct social problems have been treated with specific technological innovations. The six case studies included in Etzioni and Remp's report included the following: (a) the use of methadone to treat heroin addicts; (b) the use of antabuse to treat alcoholics; (c) the use of instructional television to improve educational effectiveness; (d) the use of intrauterine devices (IUD) for birth control; (e) the use of gun control to reduce crime; and (f) the use of breath analyzers to reduce drunk driving. In their conclusion, Etzioni and Remp discovered that "while technological shortcuts are not absolutely effective - they do not deal with the full range of problems - they do seem more likely to increase effectiveness in handling major parts of these problems at lower economic and psychic costs" (p. 37).

In another examination of the question concerning the potency of technological fixes, Weinberg (1997) considers the way in which three specific examples of technologies have been applied as solutions to three pressing social problems. The first problem Weinberg considers is war. The development of nuclear weapon technology has, in Weinberg's opinion, reduced the threat of large-scale war. Although thermonuclear weapons have not succeeded in urging "men to love their neighbors," the threat of nuclear annihilation has given the world "no rational alternative to peace" (p. 70). In this way, Weinberg argues, technology has stabilized an "imperfect and precarious peace" (p. 70). In respect to the problem of overpopulation, Weinberg shows how the IUD has significantly alleviated what appears to be a profound social problem (p. 71). As his final argument, Weinberg considers the possibilities of using nuclear power for the desalination of seawater in areas that lack sufficient supplies of fresh water. 
Weinberg explains that "technology can provide water without requiring a great and difficult-toaccomplish change in people's attitudes toward the utilization of water" (p. 72).

In conclusion, Weinberg (1997) concedes that "technological solutions to social problems tend to be incomplete and metastable, to replace one social problem with another" (p. 73). Social problems are more complex than technological problems and require social solutions. "To solve a social problem one must induce social change - one must persuade many people to behave differently than they have behaved in the past" (p. 69). In this sense, Weinberg is saying that social problems require motivational solutions, not technological solutions. However, Weinberg emphasizes that technology can "make intractable social problems less intractable; perhaps, most of all, technology will buy time - that precious commodity that converts violent social revolution into acceptable social evolution" (p. 73).

\section{Technology and Pessimism}

Modern technological innovations, such as the steam engine, the railroad, electricity, and medicine, fo stered in Western secular thought a strong sense of optimism. "Much of the extravagant hope ge nerated by the Enlightenment project derived from a trust in the virtually limitless expansion of new knowledge of - and thus enhanced power over - nature" (Marx, 1994, p. 239). Driving this sense of confidence in technology were the mounting breakthroughs in knowledge and discoveries. "The expected result was to be a steady, continuous, cumulative improvement in all conditions of life" (p. 240).

As modern perspectives gave way to postmodern perspectives, optimism for technology faded as well. Late in the twentieth century, attitudes toward technology had changed considerably. Events such as Hiroshima, the Cold War arms race, the Vietnam War, the Exxon Valdez oil spill, Chernobyl, Three Mile Island, Sky Lab, acid rain, global warming, and the depletion of ozone have indelibly tempered society's optimistic stance toward technology (Marshall, 1979). "Even if we fully credit the technical achievements of modernity, their seemingly destructive social and ecological consequences (or side effects) have been sufficiently conspicuous to account for much of today's 'technological pessimism'" (Marx, 1994, p. 238).

Marx (1994) suggests two postmodern viewpoints of optimistic and pessimistic conceptions of technology. By replacing "the impossibly extravagant hopes that had for so long been attached to the idea of "technology"' (pp. 255-256), it becomes possible to build a more plausible and realistic notion of what technology is capable. This, according to Marx, "may, in the long run, be cause for optimism" (p. 256).

The second perspective described by Marx (1994) gives less cause for optimism. Rooted in the tradition of Foucault and Lyotard, this postmodern outlook "ratifies the idea of the domination of life by large technological systems" (p. 257). Marx notes the strong connection between the size of a given technological structure and the power it wields. Marx provides an example of such a structure: "the forthcoming mode of fiber-optic communications, an electronic system that is expected to link all telephonic, television, and computer transmission and reception, and all databanks, in a single national (and event $\mathrm{u}-$ ally global) network" (pp. 274-275). Although the power of such an "immense, overlapping, quasiautonomous technological system" (p. 257) would likely not be under the control of a single individual or group, it would be inherently dangerous and would open the door for a form of proto-totalitarianism.

The digital divide reflects a recent surge of pessimism about technology's effect on society; however, such awareness is hardly new. In London in 1811, Ned Ludlum entered history as the first antitechnology activist when he attacked his textile machine with a hammer (Volti, 1995, p. 20). Ludlum's case was not the first act of violence against technology, but it did coincide with a period of rapid industrialization. During the early nineteenth century, England was at the height of the Industrial Revolution. As more people forewent their agrarian lifestyles in search of industrial employment in the proliferating urban factories, social unrest began to brew due to overcrowding, competitive labor markets, and harsh workplace conditions. Then, as more productive and efficient machines were developed, attacks on and 
sabotage of machinery became more widespread and fears that machines would permanently replace workers escalated. The many disparate outbreaks of machine-smashing and other anti-mechanistic actions occurring during the early nineteenth century are collectively referred to as the Luddite movement, named after Ned Ludlum.

Since the turn of the twentieth century, social concern about the possible negative impact technology can have on society has been explored in various brands of critical thought. Mumford (1934) noted that technology "exists as an element in human culture and it promises well or ill as the social groups that exploit it promise well or ill" (p. 6). Echoing this perspective more than fifty years later, Kranzberg (1986) gave us the first of Kranzberg's laws: "Technology is neither good nor bad; nor is it neutral" (p. 545). Offering a similar perspective of technology, Shallis (1988) reminds us that "the trouble with technology is not itself but our attitude to it, for we do not often recognize it for what it is, mistaking it for something that is an end in itself rather than a means" (p. 27).

Within the culture of postmodernism, "technology itself may be assuming a declining status amid a growing disenchantment with material success" (Segal, 1995, p. 3). It is in this critical assessment of technology's impact on society that concern for the digital divide originates. Acknowledging the significance of the digital divide requires an assumption that ICT is merely a means to a greater end; and, for some reason, ICT is either unable to deliver, or is obstructing the attainment of this greater goal. The greater goal ICT appears to be serving is the establishment of a digitally enhanced society in which opportunities for equal social participation are made possible.

\section{Technological Determinism}

The prominence of technology in the world today may be at an all-time high. "Technology is all around us: we live in a world in which everything that exists can be classified as either a work of nature or a work of man [sic]" (McNeil, 1996, p. 1). Views such as this illustrate the pervasiveness of technology in the modern world. Although technology is distinctly a human creation, individual humans typically have minimal control over the technologies that influence their lives (Volti, 1995, p. 253). Describing a popular perspective on how technology affects society, Kranzberg (1989) notes that technology "has become autonomous and has outrun human control," and that furthermore,

In a startling reversal, the machines have become the masters of man. Such arguments frequently result in the philosophical doctrine of technological determinism, namely, that technology is the prime factor in shaping our life-styles, values, institutions, and other elements of our society. (p. 245)

The idea that technology has become an independent and autonomous force sounds like the plot of a number of science fiction stories (van de Donk, Snellen, \& Tops, 1995). However, a number of authors take this idea very seriously. Technological determinism is the concept that "what began more than a million years ago as a human creation has taken on a life of its own, with technology advancing according to its own inner dynamic, and unrestrained by social arrangements, culture, and thought" (Volti, 1995, p. 253).

Through his analytical study of the historical role technology occupies in society, Ellul (1964) concludes that the preoccupation with science and technology is a problem of our modern age. We are told that "nothing at all escapes technique today" (p. 22), and the most probable future for humanity is one in which technology is supreme. Ellul perceives modern-day reality as a monolithic technical world in which the individual "has lost contact with his natural framework and has to do only with the organized technical intermediary which sustains relations both with the world of life and with the world of brute matter" (p. 428).

Ellul (1964) describes five factors that have produced the rapid growth of technology in the modern era. First, technology requires an incubation period in which technological developments amass. Ellul asserts 
that "every invention has its roots in a preceding technical period" (p. 47). In a sense, techniques and the knowledge that makes them possible are products of a slow fermentation that consists of millions of accumulated experiments. The second factor described by Ellul is a population expansion. From one perspective, "the growth of population entails a growth of needs which cannot be satisfied except by technical development" (p. 48). And from another standpoint, an expanding population encourages rapid technological development because of both expanding markets and human resources. The third factor is a stable yet flexible economic environment. A society's economy must be stable enough to support detailed attention to technique while also being "capable of great change, so technical inventions can be absorbed into the economy" (p. 49). The fourth factor is the "disappearance of social taboos and the disappearance of natural social groups" (p. 49). The term Ellul uses to describe the disintegration of social restraint and identity is social plasticity: "without it, no technical evolution is possible" (p. 51). The final factor leading to exponential growth of technique is the development of a "clear technical consciousness" (p. 57). As the value of technology became clearly linked to the growth of economic, social, and military power, societies became increasingly dedicated to the development of technology. However, Ellul points out that for a society to benefit from a clear technological invention, the previous four factors must be present (p. 60).

\section{Information Communication Technology}

Historians of technology frequently describe the society-technology relationship using categorical disciplines (McNeil, 1996). Technology is composed of many distinct disciplines often reflecting a collection of applied sciences. Medical technology draws on many sciences and technologies related to promoting health (Volti, 1995, p. 107). Transportation technology includes a host of scientific and technological disciplines focused on the movement of humans and their artifacts (McNeil, 1996, p. 431). ICT is the collection of theoretical and applied scientific knowledge that has been developed and arranged to facilitate human handling of information (Ohlman, 1996, pp. 688-689). Although the digital divide is connected with other technology disciplines, the digital divide is fundamentally an ICT-related phenomenon (Bolt \& Crawford, 2000, p. 124). The digital divide is an issue where access to ICT determines how and to what extent individuals participate in society (NTIA 1995, 1998, 1999, 2000a, 2000b).

Nearly every person in the contemporary United States of America has in some way been affected by technological developments. When Burke (1978) claims that "thanks to technology no man is an island" (p. 5), he is referring to the comprehensive dependence modern humans have on technology. Clarifying this influence, Ihde (1990) describes our existence as being textured by technology:

Not only with respect to the large dramatic and critical issues which arise in a high technological civilization - such as the threat of nuclear war or the worry over global pollution, with its possibly irreversible effects - but also with respect to the rhythms and spaces of daily life. (p. 1)

As society in the United States becomes more integrated with technology, it also becomes more dependent on information. The United States is rapidly becoming what many writers call an "information society" (Martin, 1988; Schiller, 1996; Webster, 1995). Such a society experiences a process in which economies, political systems, occupational realities, physical environments, and cultures become indelibly influenced, if not entirely dominated, by ICT (Carnoy et al., 1996; Webster, 1995).

Information and the way in which it is communicated have held valued positions in society throughout the ages. The structure of a society's economic, political, and cultural life "is shaped by the way it uses its communication systems" (Burke, 1978, p. 81). The development of verbal language made way for the development of civilization. The dawn of written language changed history by textually recording it. Gutenberg's use of the printing press with movable type, followed by the proliferation of schooling and literacy sparked an information revolution that is still being played out today (Textor et al., 1985). 
How does our contemporary age merit being identified as an information society? Answering this question, Martin (1988) recalls that societies throughout history have commonly been described as being agrarian or industrial, capitalistic or socialistic, totalitarian or democratic, etc. According to Martin, the "vast quantities of information, the sheer amount of research and development that underpins all those advances in computers and telecommunications" (p. 303) warrant the description of the present time as the information age. By any historical interpretation, this is the only age that has generated such sophisticated devices, arranged in such a comprehensive network, whose sole purpose is to supply societies' demand for information.

The growing demand for information appears to be causing an exigency for continuous developments in ICT. Despite the rapid pace of ICT breakthroughs in the area of bandwidth, the capacity of the National Information Infrastructure is continually filled. However, innovations in ICT may actually be contributing to the accelerating need for more information (Schiller, 1996, p. 75). The fundamental reason behind the 1969 creation of ARPANET, the predecessor of the Internet, was to support the electronic transmission of technology research (Hofstetter \& Sine, 1998, p. 13). Another example of ICT fueling its own demand is the billions of bits of information transmitted daily describing technology stocks, news of developments in the technology sector, and advertisements for technology companies. Determining whether ICT is creating or satisfying society's demand for information is complicated and difficult. Perhaps less difficult to determine is whether there is a social impact elicited by the informatization of society (Webster, 1995, p. 9).

There is a technologically-mediated avalanche of information profoundly affecting the structures of our society. Chairman of the Federal Reserve Board Alan Greenspan noted this effect on the economy: "The newest innovations, which we label information technologies, have begun to alter the manner in which we do business and create value, often in ways not readily foreseeable even five years ago" (Greenspan quoted in NTIA, 1999, p. 1).

Responding to the impact ICT has had on the education system, one of the seven top priorities adopted by the United States Department of Education is to insure that all classrooms in the United States will be "connected to the Internet by the year 2000 and all students will be technologically literate" (2000, p. 1). In a letter issued in 1993, Clinton and Gore announced one way the epicenter of United States politics is responding to ICT's impact: “The White House will be connected to [citizens] via electronic mail. Electronic mail will bring the Presidency and this administration closer and make it more accessible to the people" (Clinton \& Gore, 1997, p. 474).

\section{The Digital Divide}

In recent years, a growing awareness of the social implications of ICT and its spreading influence in society has developed rapidly among the American public. One of the focal points of this emerging awareness is the disparity caused by ICT; this disparity is widely referred to as the "digital divide." Under the direction of the Clinton Administration, the federal government of the United States began to examine the digital divide closely. According to the National Telecommunications and Information Association (NTIA), the United States is divided into two distinct groups. There are those who have access to the most sophisticated information technologies, and there are those who have no such access. The following passage taken from the Clinton Administration's Digital Divide Web site offers an account of what it means to be unable to access ICT:

To be on the less fortunate side of the divide means that there is less opportunity to take part in our new information-based economy, in which many more jobs will be related to computers. It also means that there is less opportunity to take part in the education, training, shopping, entertainment and communications opportunities that are available on line. (NTIA, 2000b, para. 3) 
Much of the contemporary literature concerning the digital divide is either informed by, or dedicated to, describing the surge of research reports defining the digital divide or the various efforts designed to close the divide. Research reports on the digital divide are usually of a quantitative nature. The NTIA has produced a series of reports on the digital divide that rely primarily on United States Census Bureau information. These reports seem to have been adopted as a benchmark for subsequent research: most current studies on the digital divide either refer directly to the NTIA reports or model the agency's demographic approach.

Often spawned by these research reports, there have been numerous efforts designed to bridge the digital divide. Commonly taking the form of policies and programs, these efforts aimed at closing the digital divide are essentially constructed from the recommendations proffered by the research dedicated to describing the digital divide. The programs and policies discussed above were chosen from the numerous initiatives to span the digital gap because of their unique and pioneering nature.

\section{Overview of Research Project}

This study explored a specified set of perceptions of the digital divide's future. Epistemologically, the future is unknown and evades inspection. Although knowledge of the future does not exist and cannot be studied, perceptions of an anticipated future do exist and can be studied. Due to this unique condition of the future, a method of inquiry specifically designed for building scenarios of the future was selected for this research project. Ethnographic Futures Research (EFR), a qualitative method of inquiry pioneered by Textor (1980, 1990a, 1990b, 1995; Bell, 1997; Wolcott, 1999), was chosen for its ability to systematically draw out perceptions of the driving forces affecting the current state of the digital divide and build visions of how such forces may influence the future state of the digital divide.

\section{An Introduction to EFR}

EFR, a sub-type of Futures Research (FR), can be thought of as a hybrid ethnography. Just as FR is dependent on an explicitly formulated and structured methodology, EFR is also highly disciplined and grounded in data. However, what differentiates the two approaches is the ethnographic aspect of EFR. The similarities between EFR and ethnography are strong. Both approaches "start with a broadlyphrased problem and gradually refine the problem on the basis of interaction" (Textor, 1980, p. 21). Both inquiries give considerable weight to the context, history, and worldview of the culture being studied. However, the ethno graphy is primarily concerned with the past and present cultural patterns of a given group, while the EFR approach is concerned with "possible, probable or projected culture patterns in the future" (p. 22). An additional difference between EFR and conventional ethnographies is that the latter are "based on a combination of interviewing and observation, while EFR is necessarily based on interviewing alone" (p. 22).

EFR is designed specifically to "elicit, describe, analyze, and interpret people's present images of possible or probable future cultures and their preferences among those hypothetical cultures" (Textor, 1980, p. 10). There is a specific structure and procedure to conducting an EFR interview. The goal of the interview is aimed at educing from interviewees possible or probable scenarios of a future culture situated in a not-so-distant future. In conducting an EFR interview, care must be taken to encourage spontaneity, discourage utopianism, maintain a non-directive structure, remain productively interactive, create an appropriate atmosphere for exploration and imagination, and reduce tempocentrism. Textor (1990a) defines tempocentrism as "a complex psychocultural state in which we become 'centered' in the wrong temporal frame" (p. xxxii).

The product of the EFR interview (Textor, 1990b, pp. 145-157) is a collection of three scenarios describing an optimistic future, a pessimistic future, and the most probable future. Beyond the scenarios, the EFR approach also elicits the interviewee's basic conceptual model for change. Concluding the sce- 
nario-building portion of the interview is the interviewee's description of how the optimistic scenario could be rendered more probable.

\section{How EFR was Used to Explore the Digital Divide}

This study looked at the following fundamental questions: (a) How the digital divide was described by those who work to bridge it, (b) What they saw as the forces driving the digital divide, (c) How they envisioned the digital divide's future, and (d) How they described their efforts to close the digital gap. This study investigated the future of the digital divide in the State of Washington through visions of the future as described by individuals who are professionally dedicated to ameliorating the phenomenon of digital exclusion. The date in which all of the optimistic, pessimistic and most probable scenarios are set is 2016 , fifteen years from the date of the interviews.

EFR involves the interviewing of participants. Deciding whom to interview is an important consideration when building any study. Social research has the opportunity to provide a medium for those who lack the means to have their voices heard (Rees, 1991). The future of the digital divide is the subject of inquiry in this study and the construction of scenarios is the study's purpose. The population chosen for this EFR project met the following criteria:

1. Familiar with the driving forces influencing the digital divide.

2. Knowledgeable about the various approaches employed to bridge the divide.

3. Understanding of the experiences of those who are excluded by the digital divide.

The participants selected for this study included individuals who were identified within their professions as leaders of an effort to bridge the digital divide. Because there are thousands of efforts currently under way in the United States to bridge the digital divide, this study narrowed its scope by seeking the perspectives of individuals who (a) were exploring the boundaries of the digital divide and experimenting with its possible solutions, and (b) resided in the State of Washington. As part of narrowing the study's scope, the State of Washington was chosen because of its significant role in the development of information communication technologies and because of the locality of the researcher.

Thirteen EFR interviews were conducted in this study. Each included a certain degree of structure in the beginning; however, once the interview was underway, care was taken to provide a considerable amount of flexibility and openness. The purpose of each interview was the elicitation of three possible scenarios of the future of the sociocultural system of the State of Washington. On average, each interview lasted 1.5 hours. In one case, the interview was completed in less than one hour, and in three cases, the interviews lasted for several hours. Table 1 generally describes the thirteen interviewees. In the effort to protect the identity of the interview participants, column two contains a pseudonym and column three provides a broad description of the occupation for each interviewee.

\begin{tabular}{|l|l|l|}
\hline \multicolumn{3}{|l|}{ Table 1: Description of Interview Participants } \\
\hline 1 & Pseudonym & Occupation \\
\hline 2 & Anita & $\begin{array}{l}\text { A lawyer leading several statewide initiatives aimed at broadening access to court systems through the } \\
\text { use of information communication technologies (ICT). }\end{array}$ \\
\hline 3 & Charlie & $\begin{array}{l}\text { A networking specialist for a public university who directs a program whose mission involves support- } \\
\text { ing the ICT needs of the university's residential students. }\end{array}$ \\
\hline 4 & Derek & $\begin{array}{l}\text { A former high-ranking county court official who is dedicated to improving how the state's judicial } \\
\text { system handles the emergent challenges presented by new technologies. }\end{array}$ \\
\hline
\end{tabular}




\begin{tabular}{|l|l|l|}
\hline 5 & Emily & $\begin{array}{l}\text { An elected official of the Evergreen Nation Tribal Council who is in charge of her reservation's infor- } \\
\text { mation systems. }\end{array}$ \\
\hline 6 & Fred & $\begin{array}{l}\text { A dean at a public university who previously served faculty in information systems and will soon serve } \\
\text { as the dean of his university's information department. }\end{array}$ \\
\hline 7 & Gina & $\begin{array}{l}\text { A development officer for a Seattle-based non-profit organization committed to providing access to } \\
\text { technology in historically disadvantaged communities. }\end{array}$ \\
\hline 8 & Henry & $\begin{array}{l}\text { A manager of a municipal telecommunications division in which he oversees the cable television ser- } \\
\text { vices and serves as an advisor on telecommunications to city council. }\end{array}$ \\
\hline 9 & Ivan & $\begin{array}{l}\text { An expert in the fields of distance education, information technologies, news media relations, rural } \\
\text { telecommunications, and satellite and television communications. }\end{array}$ \\
\hline 10 & Jack & $\begin{array}{l}\text { A former state utilities commissioner and current director for a university-sponsored program to ad- } \\
\text { dress the digital divide. }\end{array}$ \\
\hline 11 & Kyle & $\begin{array}{l}\text { A principal investigator for the United States Department of Commerce's Telecommunications Oppor- } \\
\text { tunity Program exploring community informatics. }\end{array}$ \\
\hline 12 & Larry & $\begin{array}{l}\text { A project manager of a cooperative project designed to improve community connection, funded by } \\
\text { both a national agency and a state university. }\end{array}$ \\
\hline 13 & Mark & $\begin{array}{l}\text { A technology planner for a municipal technology department. Mark is dedicated to helping people } \\
\text { communicate in a society that is increasingly defined by ICT. }\end{array}$ \\
\hline
\end{tabular}

Each interview was taped, transcribed, analyzed, and summarized into three categorical scenarios: optimistic, pessimistic, and most probable. Following Textor's (1990b) advice, each interview was interpreted and summarized into a draft (called a "protocol") that was returned to the respective interviewee for validation. In most instances, interviewees corrected and elaborated on the content contained in the draft summary of his or her interview.

\section{Findings}

Data from each interview and subsequent protocol were organized into composite scenarios of the optimistic, pessimistic and most probable futures, which are interpreted here as findings. Only those findings relevant to the relationship between technology and society are presented here. Each scenario is organized into themes. In some cases, excerpts from interviews are included.

\section{Optimistic Scenario}

In formulating their optimistic scenarios, each interviewee noted that ICT has historically demonstrated a strong and pervasive influence on society. In anticipating the future, interviewees described how ICT will be one of the prime factors affecting conditions in 2016. The optimistic scenarios of the future depends less on the development and direction of specific technologies and more on the way in which ICT is employed by society. The general sentiment appears to be best phrased by Charlie: "ICT is a tool" and "a tool is only as good as the people." Emergent themes in the composite optimistic scenario include ICT's being accessible and beneficial to all, which will enable technological literacy to expand. Commenting on the potential observational power of ICT, another emergent theme in the optimistic scenario focused on the protection of personal privacy.

\section{ICT will benefit everyone}

Given the potentially beneficial impact ICT can have on society, the optimistic scenario focused on the idea that ICT will be applied in such a way that will benefit everyone. Derek optimistically believed that people will have greater access to ICT devices and the services such technology provides. "I expect that we would have much more access to that type of technology but I don't know that it would be obtrusive, 
I don't think it needs to be the organizing principle of society." According to Derek, almost anyone will have access to ICT; it will be as ubiquitous as other forms of technological devices. "[ICT] would be inexpensive enough that anybody in the extremes of wealth and poverty would be leveled out to the point that anybody could have it. . . It would be somewhat more representative of telephones and televisions as they are now." When asked whether the lack of access to ICT would disadvantage individuals in the optimistic future, Derek responded,

Yes, in that it would be less convenient for them to do certain things, but in my optimistic scenario, I don't want it to be required that you participate in that way of doing things. For example, I would like to still be able to go to a neighborhood polling place and vote if I want. I can still go to a grocery store and buy some things, whatever the future incarnation of that is.

To ensure that ICT beneficially impacts society, Derek's optimistic scenario requires that corporations not have exclusive control over the creation of content on, and access to, ICT. In fact, Derek conceived that almost everyone will have access to ICT, whether through libraries, community centers, home access, or coffee shops; access to ICT will be as ubiquitous as the telephone. "I can imagine a sort of new culture emerging from [ICT], as long as it is not under corporate control."

Gina felt strongly that "information technology is going to have a huge impact on life." She believed that ICT will be a liberating force for place-bound resources and opportunities. Distances will become smaller as we employ new technologies that enable communication across vast expanses as if we were sitting in the same room. People will more frequently congregate and communicate in real time using the virtual environments of cyberspace.

\section{Access to ICT will become more ubiquitous}

Access to ICT was envisioned to be greatly improved in the optimistic scenario. Expansion of access was described in terms of broadband connectivity as well as wireless. Regardless of the method by which access is expanded, the fact that historically underserved communities would be given the opportunity to connect was clearly an important aspect of the optimistic scenario.

Ivan anticipated a significant expansion in ICT infrastructures. Broadband connectivity will be available to an increasing number of currently disconnected communities (e.g., rural towns, inner city neighborhoods, etc.) at affordable prices. This expand ed level of connection will impact nearly every aspect of society in Washington. ICT will lead to better education that will spawn increased economic activity. ICT will prompt the growth of a telecommuting workforce that will reduce pollution and traffic while allowing individuals to live where they want to, not where they have to. Providing another example of future ICT access, Gina noted that by the horizon date of 2016, streaming audio and video will be available to the average United States household; not too long after that, high quality audio and video communication will be available in portable handheld devices.

\section{Technology literacy will flourish}

For ICT to benefit members of society, individuals must not only have access to ICT, but they must have the skill and ability to use these technologies in productive and meaningful ways. This "skill and ability" was referred to by many interviewees as "technology literacy." In the optimistic scenario, technology literacy will flourish.

A key condition of Gina's optimistic scenario is an increased level of technological fluency. To benefit from the impact ICT will have on Washington's society, Gina noted that one must become more than literate; one must be fluent. Literacy has a variety of meanings. The conventional meaning of literacy refers to having a functional knowledge base of a language: for example, the ability to read and write. Technological literacy refers to having a functional knowledge base of a technological system. Fluency 
takes literacy one step further: fluency refers to the ability to successfully incorporate literacy into one's daily life. "People who are literate in our society are not necessarily successful - people who are fluent are ... you need to be fluent in reading, writing, speaking, and in technology."

Larry has a slightly different opinion on the issue of literacy and fluency. Considering the direction and extent to which ICT will develop over the next fifteen years and how such developments will impact society, Larry foresaw ICT having a dramatic effect on communication. Larry believed that the barrier to literacy will be brought down by the increasing ability of computers to facilitate and emulate natural human communication:

In the future, I see a person talking to a computer more so in plain language and getting results than not, and that the intelligence will be there for machines to recognize different voice inflections and accents and so on so that you still get credible answers back. More efficient, less laborious, smaller devices - maybe even smart clothes by that time that would aid in communications.

\section{Privacy will be protected}

ICT has the potential to invade personal privacy on a scale never before possible. The optimistic scenario requires that privacy is protected. Kyle described an optimistic scenario that deals with the threat connectivity can bring to personal privacy. According to Kyle, as ICT devices become increasingly pervasive, the trend for universal surveillance becomes more possible and probable. Kyle's concern for the "panopticon," or the all-seeing eye, is necessarily connected to the proliferation of ICT that is a part of his optimistic scenario:

That trend, coupled with the ability of technologies to become increasingly distributed, [leads to] the disappearance of the computer itself into intelligent devices connected to the network. Our toasters are on the net. Little baby's bassinette has a camera there so you're at work in an office building in downtown Seattle and you want to see what the au pair is doing with your kid, right, you know, you can watch. Your kid knows, growing accustomed to being surveilled remotely by Big Daddy for the rest of his life and will have no problem coming into a culture of panopticon.

Kyle's optimistic scenario envisioned government policies that protect privacy. Given the tendencies of corporations to exploit markets, the protection of privacy is imperative. Without such intervention through public policy, "the most vulnerable consumers are then giving away their bodies in a sense, prostituting their spirits. It makes them weaker, socially and economically. We can't afford that because we need more locally owned small businesses. . . . There's got to be sufficient privacy, information privacy protection in the face of an increasingly more sophisticated consumer." An alternative to this new way of thinking about privacy will have undesirable impacts on businesses, governments, and society in general.

\section{Summary of optimistic scenario}

The relationship between society and technology is a major driving force in the optimistic scenario. The nature of this relationship is determined by the way in which technology is applied to society, which is to say, the way in which society chooses to make technology accessible and usable to the members of society. There are many hopes pinned on this relationship being constructively arranged; in the optimistic scenario, such a beneficial relationship will become a reality.

\section{Pessimistic Scenario}

In the composite pessimistic scenario, the relationship between society and technology will be poor. As technology is misused and inappropriately applied to social institutions, the promises technology holds 
for society will be foregone. A common source of pessimism elicited by this study was the continuation of certain current trends. In some explanations of the pessimistic scenario, there was more than just the persistence of existing social problems; some scenarios included an exacerbation of social maladies. The continuation of inequities in access to opportunities was discussed as a significant contributor to the pessimistic scenario, as was the continued practice of unsustainable processes. Emergent themes on the composite pessimistic scenario included inadequate protection by public policy because policy decisions will be driven by concern for the "bottom line." Without adequate protection and concern for the public good, ICT will assume the role of oppressor rather than liberator.

\section{Inadequate protection}

Ideally, the laws and policies used to regulate ICT should balance the needs of private sector commerce with the protection of the public's interests. In the composite pessimistic scenario, this balance will be foregone. The interests of corporations will supercede the interests of communities. The public good will no longer be adequately protected.

A disturbing trend described in Henry's pessimistic scenario was the erosion of protections that prevent information monopolies. Henry pointed out that there are three main components of an ICT delivery system: the production of information, the mechanism (device) of delivery, and the ultimate service provider:

It used to be public policy that it was important to have all three of those operated by individual entities because information and the control of information is so paramount to our culture, a democratic culture. There used to be prohibitions against a newspaper company owning a television station and a radio station in the same community. Well, there is continual pressure for those kind of restrictions to go away.

In Henry's pessimistic scenario, the motivating force for dissolving those public protections will be a variety of commercial pressures. There will be a drive to dismantle public policies that prohibit ICT monopolies, and this drive will be fueled by concerns for market share and profits, not by concerns about what is the best for society, communities, and individual citizens. The specific application of commercialization is its focus on turning a profit. For example, if a given product, service, or initiative is unable to turn a profit it will be abandoned because, from a commercial perspective, it has no value.

\section{Policy decisions driven by commercialism}

The loss of protection for the public's interests will be driven by commercialism. In the pessimistic scenario, information will be viewed as a corporate asset, not as the lifeblood for sustainable community development. Protective policies will treat information as private, not public, property.

As perceived by Kyle, a lot of the current policies that control ICT infrastructure are "warped and misguided because of larger economic incentives that are guiding behavior in the wrong ways." The digital divide is being used, and in the pessimistic scenario it will continue to be used, as a justification for the creation and exploitation of a new market: the consumerization of the poor. "The digital divide is a useful construct for subsidizing the computer and consumer electronics industry to tap a new market, or what they perceive as a market."

Henry explained that when commercialism is used as a decision-making tool in the areas of government, citizenship, community, and social services, social injustice and disservice are clearly unavoidable. Information and ICT have a very important role in the non- market sectors of society. However, in the pessimistic scenario, all aspects of society are evaluated by commercialism's bottom line analysis. If a program, project, or initiative is not making enough money, it simply will not be supported. In the pessimistic scenario, "factors determining who gets to be the information provider, the information creator, dis- 
seminator, and ultimate provider" will be strongly influenced by commercialism and not by concern for the common good.

In Henry's pessimistic outlook, information that is disseminated will originate from a single centralized entity, which will dramatically diminish the reliability and credibility of information. Information will become less representative of the diversity of its recipients. In many cases, information will not be trusted. Increasingly, information will be mass-produced as a product for the mass market of consumers. According to Henry, there is something very wrong with this trend:

Information is not like breakfast cereal. . . information is the driving force behind our culture. People being well informed and able to come to their own conclusion on any given subject is absolutely critical to the operation of an open participatory culture or society.

Along a similar line of thought as that described by Henry, one of the primary forces driving Jack's pessimistic scenario is our society's tendency to employ a market-based approach to solving problems. The underlying principle in a market approach is exclusion: value is created when there is demand for a product or service. "This notion of commercializing the technologies within the general nature of the capitalis tic economic system needs to provide exclusive access to create value." Limiting access, which is exclusion, creates demand. Because a market-driven exclusion-based approach was the underlying premise of Jack's pessimistic scenario, the net result will naturally be that people are excluded, and those who are excluded will most likely be those who are already disadvantaged.

Like Jack, Mark focused his pessimistic scenario on a myopic application of ICT. Mark illustrated how technology will be used for amassing gains in market share, media dominance, and political power. In Mark's pessimistic scenario individuals will not be given the opportunity to develop the skill of media literacy: the ability to critique and evaluate the messages (images and sounds) mediated through the various technologies. Noting that media literacy has long been an issue in radio and television, Mark explained that media literacy will be an important issue as more information is communicated through ICT. The main concern with media literacy is the ability to discriminate valuable content from fluff.

According to Charlie, one of the amazing aspects of ICT is the quantity of information and services freely available. In the pessimistic scenario, the things that are currently free via ICT will incur charges and those who do not have the resources to pay for these services will be unable to afford the full value that ICT has to offer. Charlie believed this trend will contribute to a rising frustration among the public.

\section{ICT will be used to oppress}

In the pessimistic scenario, ICT will become more pervasive and resultantly persuasive. Access to ICT will determine participation in society; however, the ICT-mediated channel for social inclusion will be populated by carefully designed content. Effectively, ICT will be used to oppress both the connected and disconnected populace.

Mark believed that in the future, access to ICT will be a requirement for effective citizenship in the United States. Those who are on the "wrong side" of the digital divide will essentially be socially disadvantaged. As described by Mark, the central issue of the digital divide is not about access to ICT - it is about access to society's services and resources.

In Brenda's pessimistic scenario, the availability of ICT devices will increase, and the digital divide will continue to diminish. As in her optimistic scenario, the role of ICT in her pessimistic scenario will be for communication; however, what will be communicated is oppressive propaganda. Brenda pessimistically projected that ICT will be used to put people down; ICT will be used to "get the word out, get the propaganda out. We know that humans are capable of persuasion of each other, whether it's books, or telephone, or technology, it can be used to persuade, just like it can in utopia." 
Society, in Larry's pessimistic scenario, will be dramatically less tolerant. When there is resistance to the oppressive actions of the power holders, there will be a forceful response by the authorities. ICT will be the agent used to propagate this scenario. "A framework is being set for a harsher society using information technology . . . it creates a greater challenge for us on the other side who want to promote it for ge neral and widespread use." Larry stressed that ICT use will be designed to protect those with power, even if such designs trample the needs of the powerless:

We're not the developers of anything; we're the users of it. So in 2016, it could possibly even happen now, you'll have a situation where a person could be criminalized in their home with a little thing around their leg and arm that limits their movement, or you have situations where the phone companies pulled a lot of pay phones in inner cities because supposedly they were using them for drug transactions, but in reality they weren't a good service base and profit center for them. So they pulled the service and they called it something else. They also pulled the service and it aided the advent of calling cards and some of these other devices that have come about, or prepaid so that poor people do prepay now, so the phone company doesn't lose any money and the phone booth doesn't get vandalized and wha tever. They don't have to provide any services. I don't know what will be the answers for those situations if we don't have public access facilities.

\section{Summary of pessimistic scenario}

Pessimistically, market forces will heavily influence the relationship between society and the technologies upon which it relies. As seen by many interviewees, the wondrous potential offered by ICT will vanish due to a society's obsession with the bottom line. Instead of being manifested as a technology of freedom, ICT will be marshaled by the powerful elite to trumpet propaganda, to create and exploit new markets, and to further stratify society. A general sense communicated in these interviewees' pessimistic scenarios was that the way ICT will be applied to society will be nothing less than an opportunity lost.

\section{Most Probable Scenario}

The most probable future as described by these interviewees was also influenced by the realities of ICT. As mentioned in previous scenarios, ICT was generally perceived as a tool for human use. As a tool, the effect of its use is dependent on the will and skill of its user. In the most probable scenario, the reality of ICT is that it will be used in both positive and negative ways.

\section{The net effect will be positive}

The composite most probable scenario was ge nerally positive. For example, Brenda's most probable future is closer to her optimistic scenario than to her pessimistic one. "I think there is a change in the positive that is going to happen." Technology will continue to be used in the future, and many of its applications will be positive. Given that technology is a tool for human use, it is inevitable that in some ways ICT will be poorly applied, too:

I think that we are going in a direction that is positive. I think it is plausible that the technology that is around will stay, that technology can be used as a positive tool. I think that it is also possible that it will be misused. We are all human. We get these grandiose ideas and they flop.

One area in which ICT is generally expected to be applied well is education. While there is the potential for ICT to do both great and terrible things in the classroom, the net effect will be positive. For example, ICT will enable historically underserved populations to take advantage of educational opportunities. There are many people who see both great possibilities and the potential for negativity as a result of having ICT in the classroom. 
Derek was rather blunt with his projection: "A lot of computers and networking [will be put] in the classroom but without a clear idea of how to use it." Universities will increase their use of ICT, but the physical campuses will still have an important role in the future. ICT will be used to enhance communication in the classroom and to distribute materials.

For Henry, the pessimistic scenario was less probable. In support of this projection, Henry cited the pervasiveness of technology. The ubiquity of ICT will prevent a centralization of control of information, which is one of the main components of the pessimistic scenario. He explained,

The ultimate pessimistic view . . . I just don't think that can happen because of the pervasiveness of the technology. It's just going to be very difficult for the pessimistic view that I am articulating with the centralized control. It is very difficult for that to happen with the pervasiveness of telecommunications technology.

Along a similar line, Kyle believed that in the most probable scenario, broadband ICT will become a standard utility. Society will be totally wired within 15 years:

I think that this rural in-migration trend is going to accelerate and become the norm. Broadband ICT will be as available as sewer, water, and electricity before that time. We'll have it in Canada within four or five years on the whole. It will happen in the United States within ten years. So we will have a totally wired, interactive culture within ten years.

\section{The potential for failure will persist}

In light of the benefits technology will contribute, the tendency of technology to increase the rate at which social systems must function was described by Brenda as a potentially negative force. "Technology drives us to do more, faster." Exactly what the result will be of a continually accelerating society is difficult to project; however, one clear possibility is the "nose-diving" of our culture.

In Derek's most probable scenario, ICT will continue to be developed and deployed. More and more people will have access to ICT in their homes. The main uses of household ICT will be for shopping, communicating with friends and family, and accessing media. ICT will be melded with television. Along with this development, Derek believed that we will experience an erosion of privacy due to the fact that online activity is easily tracked.

\section{Summary of the most probable scenario}

ICT offers some potentially advantageous applications to the State of Washington. Some of the interviewees believed that ICT will improve the quality and delivery of many socially beneficial services. Also, there was a notion that the ubiquity of ICT will prevent the tyranny of centralized information control. However, the interviewees also noted that ICT carries with it the possibility for society to inflict significant damage upon itself. Because of its remarkably efficient operation, ICT is effectively accelerating the speed of life. Many aspects of life in Washington have been accelerated: communication, financial transactions, news dissemination, education, transportation, etc. The net effect of this trend may be an unsustainable pace of life.

\section{Implications for Strategies to Bridge the Digital Divide}

The digital divide, like all conditions in society, has a future. Exactly what the future will be is unknown; however, through decisions made in the present, the future can be influenced. This paper reviewed a selection of literature describing the relationship between technology and society and presented findings from an EFR research project that studied possible futures of the digital divide. As a conclusion, implications for designing and implementing strategies for bridging the digital divide are offered. A common theme developed through each of these implications is the role of public policy. 
The digital divide should be seen as social problem exacerbated by technology. Inequities in access to resources and opportunities have persisted throughout the ages. Despite the timelessness of social inequities, efforts to ameliorate these disparities should continue to be an objective of all public policies. Most likely, there is no technological fix to the digital divide. Faster, easier to use and more ubiquitous ICT can help bridge the digital divide, but the critical variable described by these interviewees is the will and skill to apply ICT in beneficial and meaningful ways. Perhaps the single most effective social institution capable of influencing the ameliorative use of ICT is public policy development

Strategies for bridging the digital divide must recognize and respond accordingly to the socie tal systems in which the digital divide persists. This means that strategies must be responsive to the social, economic, political and technological realities that shape and define society. At the center of each of these realities is human culture. Human culture, while highly differentiated, strongly determines which policy interventions will succeed and to what extent. Perhaps future efforts to bridge the digital divide should combine ethnographic approaches with other quantitative methods for assessing the impact of ICT on society and drafting future policies.

One of the dominant concerns discussed by these interviewees was the economic structures in which the digital divide is situated. As a socie tal reality, the conditions of market-oriented capitalism need to be addressed in any strategy for bridging the digital divide in a capitalistic society. The issue, as discovered in this study, focuses on how well capitalism is balanced with concerns for the common good. Again, one of the more effective social institutions for regulating this balance is public policy.

As a suggestion for future efforts to explore the role of public policy in the development of a sustainable strategy for bridging the digital divide, three key roles should be investigated. The first role is that of private sector ICT entrepreneurs who have the much-needed capital to invest in ICT infrastructures, services and products that can contribute to the bridging of the digital divide. Although, ICT entrepreneurs are not likely to invest capital without adequate incentive, a condition that can be supplied by communities and the makers of public policy, the second and third roles.

Communities can develop demand for ICT by identifying how it can be applied in beneficial and meaningful ways. Essentially, communities can demonstrate the viability of a market, which will attract entrepreneurs. By taking the initiative to develop demand, communities can exercise more control over how ICT is integrated into their own unique social context. Policy makers have the ability to create enabling regulatory environments that attract investment by ICT entrepreneurs. Additionally, policy makers have the responsibility to draft and implement policies that protect the public's interest. Herein lays the balance that can determine whether the future of the digital divide is closer to the optimistic or the pessimistic scenario: Apart from being hopeful that public policy makers will do the right thing, communities can demand that the public good is protected by being informed, organized and proactive.

The future of the digital divide will be tomorrow's reality. Without a clear and realistic vision of what we desire for our future, it is unclear (and unrealistic) that our future will be desirable. What's your vision of the possible, probable and preferable futures and how can you contribute?

\section{References}

Alcorn, P. A. (1997). Social issues in technology. Upper Saddle River, NJ: Prentice Hall.

Bell, W. (1997). Foundations of futures studies. London: Transaction Publishers.

Bolt, D., \& Crawford, R. (2000). Digital divide: Computers and our children's future. New York: TV Books.

Borgmann, A. (1992). Crossing the postmodern divide. Chicago: University of Chicago Press.

Burke, J. (1978). Connections. Boston: Little Brown and Company.

Burke, J. (1985). The day the universe changed. Boston: Little, Brown and Company. 


\section{Possible, Probable and Preferable Futures}

Carnoy, M., Castells, M., Cohen, S. S., \& Carduso, F. H. (1996). The new global economy in the information age: Reflections on our changing world. University Park, PA: Pennsylvania State University Press.

Carson, R. (1962). Silent spring. Greenwich, CT: Fawcett.

Clinton, W., \& Gore, A., Jr. (1997). Letter from the President and Vice President in announcement of White House electronic mail access. In G. E. Hawisher \& C. L. Selfe (Eds.), Literacy, technology, and society: Confronting the issues (pp. $474-$ 475). Upper Saddle River, NJ: Prentice Hall.

Creswell, J. W. (1998). Qualitative inquiry and research design. Thousand Oaks, CA: Sage.

Ellul, J. (1964). The technological society. New York: Knopf.

Etzioni, A., \& Remp, R. (1972). Technological shortcuts to social change. Science, 175(4017), 31-37.

Hofstetter, F. T., \& Sine, P. (1998). Internet literacy. Boston: McGraw-Hill.

Ihde, D. (1990). Technology and the lifeworld. Bloomington, IN: Indiana University Press.

Ihde, D. (1993). Philosophy of technology: An introduction. New York: Paragon House.

Ketudat, S. (1990). The middle path for the future of Thailand: Technology in harmony with culture and environment. Honolulu, HI: Institute for Culture and Communication, East-West Center.

Kranzberg, M. (1986). Technology and history: "Kranzberg's laws". Technology and Culture, 27, 544-560.

Kranzberg, M. (1989). One last word - Technology and history: "Kranzberg's laws". In S. H. Cutcliffe \& R. C. Post (Eds.), In context: History and the history of technology (pp. 244-258). Cranbury, NJ: A ssociated University Press.

Marshall, E. (1979). Public attitudes to technological progress. Science, 205(20), 281-285.

Martin, W. J. (1988). The information society - idea or entity? Aslib Proceedings, 40(11/12), 303-309.

Marx, L. (1994). The idea of "technology" and postmodern pessimism. In M. R. Smith \& L. Marx, Does technology drive history? The dilemma of technological determinism (pp. 237-257). Cambridge, MA: MIT Press.

McNeil, I. (1996). An encyclopedia of the history of technology. London: Routledge.

Mumford, L. (1934). Technics and civilization. New York: Harcourt, Brace and Company.

Nader, R. (1965). Unsafe at any speed: The designed-in dangers of the American automobile. New York: Grossman.

National Telecommunications and Information Administration. (1995). Falling though the net: A survey of the "have nots" in rural urban America. Washington, DC: US Department of Co mmerce.

National Telecommunications and Information Administration. (1998). Falling through the net II: New data on the digital divide. Washington, DC: US Department of Commerce.

National Telecommunications and Information Administration. (1999). Falling through the net: Defining the digital divide. Washington, DC: US Department of Commerce.

National Telecommunications and Information Administration. (2000a). Falling through the net: Toward digital inclusion. Washington, DC: US Department of Commerce.

National Telecommunications and Information Administration. (2000b). Falling through the net. Retrieved November 7 , 2001, from http://www.digitaldivide.gov/about.htm

Ohlman, H. (1996). Information: Timekeeping, computing, telecommunications and audiovisual technologies. In I. McNeil (Ed.), An encyclopedia of the history of technology (pp. 686-758). London: Routledge.

Rees, T. (1991). Ethical issues. In G. A. Allan \& C. Skinner (Eds.), Handbook for research students in the social sciences (pp. 140-149). New York: Falmer.

Rutherford, F. J., \& Ahlgren, A. (1990). Science for all Americans. New York: Oxford University Press.

Schiller, H. (1996). Information inequality: The deepening social crisis in America. New York: Routledge.

Segal, H. (1995). Introduction. In Y. Ezrahi, E. Mendelsohn, \& H. Segal, Technology, pessimism and postmodernism (pp. 110). Amherst, MA: University of Massachusetts Press.

Shallis, M. (1988). The silicon idol. In J. Zerzan \& A. Carnes (Eds.), Questioning technology: A critical anthology (pp. 2632). London: Freedom Press. 
Textor, R. B. (1980). A handbook on ethnographic futures research. Stanford, CA: Stanford University.

Textor, R. B. (1990a). Introduction. In S. Ketudat, The middle path for the future of Thailand: Technology in harmony with culture and environment (p. xxii-xlv). Honolulu, HI: Institute for Culture and Co mmunication, East-West Center.

Textor, R. B. (1990b). Methodological Appendix. In S. Ketudat, The middle path for the future of Thailand: Technology in harmony with culture and environment (pp. 135-152). Honolulu, HI: Institute for Culture and Communication, EastWest Center.

Textor, R. B. (1995). The ethnographic futures research method: An application to Thailand. Futures, 27(4), 461-471.

Textor, R. B., Angkanarak, C., \& Bayardo, B. (1985). Anticipatory anthropology and the telemicroelectronic revolution: A preliminary report from Silicon Valley. Anthropology and Education Quarterly, 16, 3-30.

United States Department of Education. (2000). ED Programs that help bridge the digital divide. Retrieved November 7, 2001, from http://www.ed.gov/Technology/digdiv.html

Van de Donk, W. B. H. J., Snellen, I. Th. M., \& Tops, P. W. (1995). Orwell in Athens: A perspective on informatization and democracy. Burke, VA: IOS Press.

Volti, R. (1995). Society and technological change. New York: St. Martin's.

Volti, R. (2001). Society and technological change. New York: Worth.

Webster, F. (1995). Theories of the information society. New York: Routledge.

Weinberg, A. (1997). Can technology replace social engineering? In G. E. Hawisher \& C. L. Selfe (Eds.), Literacy, technology, and society: Confronting the issues (pp. 68-75). Upper Saddle River, NJ: Prentice Hall.

Wolcott, H. F. (1999). Ethnography: A way of seeing. Walnut Creek, CA: AltaMira Press.

\section{Biography}

Dr. Matthew M. Mitchell currently serves as the Global Networks Deputy Director for Washington State University's Center to Bridge the Digital Divide located in Pullman, Washington U.S.A. He is also the Assistant Director for the Network for Capacity Building and Knowledge Exchange in the Telecommunications Sector of Africa, known as "NetTel@ Africa." His research foci include e-learning, social justice in information societies, ICT-enabled economic development, and community leadership. Dr. Mitchell is currently administering the development of an international collaborative Masters degree program in ICT Policy and Regulation that will be based in Botswana, Kenya, South Africa, Tanzania, and Zambia. The author can be contacted via e-mail at matthew_mitchell@wsu.edu. 